\title{
"All I want for Christmas is Two": The Advent of Novel Fixed-Combination Inhalers for COPD and Outlook for 2014
}

Kai M. Beeh

To view enhanced content go to www.advancesintherapy.com

Received: November 15, 2013 / Published online: November 26, 2013

(C) The Author(s) 2013. This article is published with open access at Springerlink.com

Dear Colleague,

Looking back, there has never been a year with a greater number of novel drug approvals or filings in the history of pharmacological treatment of chronic obstructive pulmonary disease (COPD). As COPD treatment often involves a combination of therapies in clinical routine, the recent approval of two novel fixedcombination inhalers is of particular interest: the once-daily combination of an inhaled corticosteroid (ICS), fluticasone furoate, with a long-acting beta-agonist (LABA) vilanterol (Breo ${ }^{\circledR} /$ Relvar $^{\circledR}$, GlaxoSmithKline/Theravance), was approved by the Food and Drug Administration for the US market (press release October 30, 2013 [1]), and the once-

K. M. Beeh $(\bowtie)$

insaf Respiratory Research Institute, Wiesbaden, Germany

e-mail: k.beeh@insaf-wi.de

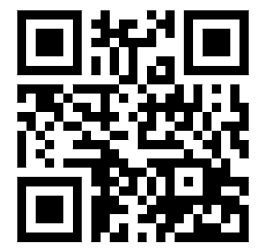

Enhanced content for Advances in Therapy articles is available on the journal web site: www.advancesintherapy.com daily fixed combination of two already marketed bronchodilator monotherapies, the long-acting beta-agonist indacaterol and the long-acting muscarinic antagonist (LAMA) glycopyrronium (Ultibro $^{\circledR}, \quad$ Novartis), was granted approval by the European Medicines Agency for countries of the EU [2]. In addition, another once-daily LABA/LAMA combination (vilanterol/umeclidinium, Anoro $^{\circledR}, \quad$ GlaxoSmithKline/Theravance) has received a positive opinion of the Pulmonary and Allergy Drugs Advisory Committee recommending approval (press release September 10, 2013 [3]), while finally a third, twice-daily LABA/LAMA combination (formoterol/aclidinium, Acliform ${ }^{\circledR}$, Almirall/ Forest) was filed for approval by EU regulators (press release November 4, 2013 [4]).

Despite the fact that neither of these drugs represent new pharmacological principles, the development process of these therapies has nonetheless fueled the current evidence-base of COPD by providing an abundance of data from large, well-controlled clinical trials. These data, in result, will undoubtedly impact on the COPD treatment approach, as reflected in global or regional guidelines and strategy 
papers like, for example, the GOLD document, and may ultimately change clinical practice.

The latest GOLD 2013 strategy paper proposes a multidimensional categorization of COPD patients into four categories, A-D, based on the severity of symptoms, and the presence of risk factors, namely severe/very severe airflow obstruction and a history of frequent and/or severe exacerbations [5]. Consequently, recommendations for pharmacological treatment are based on drugs providing symptom relief and/or a preventative effect on the occurrence of exacerbations. Long-acting bronchodilators are the mainstay of COPD treatment, while the role of anti-inflammatory treatment, namely inhaled corticosteroids, is more controversial, as their benefit is evident for exacerbation prevention in subpopulations only, while usage is associated with risk of sideeffects (pneumonia) [6], and the contribution of the ICS component to the clinical utility in ICS/ LABA combinations is not always clear to define [7]. With the advent of novel once-daily ICS/ LABA and LABA/LAMA combinations and the availability of a growing body of data, this controversy will rather aggravate than rest in the near future.

For now, what can we learn already from published trials with these novel combinations? First, the pivotal trials with the once-daily ICS/ LABA combination Breo ${ }^{\circledR} /$ Relovar $^{\circledR}$ on overall provided confirmation of what is currently known for marketed twice-daily ICS/LABAs: there is a further (although not fully consistent) reduction of exacerbations in highrisk COPD subjects when ICS is added to LABA versus LABA alone [8], but limited benefit on symptomatic outcomes or pulmonary function versus LABA alone [9]. Increased incidence of pneumonia in treatment arms containing ICS was also reported. These results are in line with the placement of ICS/LABA combination therapy in guidelines as option for categories $\mathrm{C}$ or $\mathrm{D}$ patients, if risk is defined by exacerbation history. However, it should be noted that benefits over twice-daily ICS/LABA comparator were not shown [10], which could be relevant for pricing and reimbursement, particularly in light of generic twice-daily ICS/LABAs.

What about the other novel option, a oncedaily LABA/LAMA combination? Although the (free) combination of bronchodilators is common practice for COPD, there has been limited evidence for this approach. Consequently, a combination of bronchodilators was recommended as "alternative option" for B to D subjects in GOLD 2013. However, with the development of Ultibro ${ }^{\circledR}$ and Anoro ${ }^{\circledR}$ this knowledge gap is filled with a wealth of clinical data: least surprising, combination drugs were superior to monotherapies with regard to lung function improvement [11, 12], and the surplus of bronchodilation by combination therapy was at times impressive. However, the more relevant question was in fact whether improved bronchodilation with dual combinations would translate into meaningful clinical benefits, namely symptoms and exacerbations. To date, this has been more thoroughly addressed by the Ultibro ${ }^{\circledR}$ clinical studies, whereas data published for Anoro ${ }^{\circledR}$ are more limited. Moreover, approved monotherapy comparators arms in the Ultibro ${ }^{\circledR}$ program (indacaterol, glycopyrronium, tiotropium) allowed to draw some conclusion on the clinical utility of the novel fixed combination. With regard to symptoms, the LABA/LAMA combination was superior to both LAMA monotherapy [13] and ICS/LABA [14] in improving dyspnea in symptomatic group D and/or B patients. More importantly, in the 
SPARK study, the LABA/LAMA fixed combination provided a further reduction in the exacerbation rate in high-risk C-D patients versus LAMA alone, and this was accompanied by improvements in health status versus comparators [15]. While these results are promising, the combination of bronchodilators, despite superiority in lung function, did not always result in superior efficacy versus monotherapies in all outcomes, particularly exercise $[16,17]$.

This brings up the question of positioning these combinations in the treatment of COPD. Unlike in asthma, a step-up approach in COPD is neither recommended nor supported by evidence. Should we therefore start with a dual combination early on or should such combinations be considered as an escalation of treatment after one drug alone has failed-and what clinical parameter should guide this decision? One could argue that, as poor lung function is considered to constitute risk in COPD patients per se, optimizing bronchodilation by dual fixed LABA/LAMA combinations is worthwhile for all C-D patients "at risk". If this is the case, ideallybut not necessarily-this should be supported by benefits on other outcomes. If on the other hand, one followed a step-up approach, it would be necessary to identify those patients gaining more benefit from dual versus single bronchodilation or an ICS/LABA combination. In fact, some of these information can already be derived from published studies. However, as variability of COPD categorization exists over time, particularly between $\mathrm{B}$ and $\mathrm{C}$ (with the former also having substantial mortality risk [18]), this would support introducing dual LABA/LAMA combinations into COPD treatment rather early on than stepping-up.
In any case, current data available so far do not clarify the comparative role of LABA/LAMA versus ICS/LABA as optimal strategy of exacerbation prevention. Currently, both LAMA monotherapy and ICS/LABA combinations are recommended first choice for exacerbating patients, but the SPARK study has shown that a dual LABA/LAMA combination may be more beneficial than one "gold standard", LAMA alone. While this appears encouraging for supporters of an "optimizing bronchodilation first" approach, it must be noted that in this study, many subjects had a background treatment of ICS, so the results may rather be reflective of a "triple" versus "dual" comparison. While head-to-head exacerbation data of LABA/LAMA versus ICS/ LABA are lacking to date, a trial is currently underway and results are awaited for 2015 (Clinicaltrials.gov, NCT01782326). Also, a long-term mega trial with approximately 16,000 COPD patients is presently recruiting to clarify the role of a once-daily ICS/LABA combination versus LABA monotherapy in preventing (cardiovascular) mortality [19], although results will not aid clarifying the comparative efficacy of ICS/LABA versus "optimized" dual bronchodilation. Finally, as "triple" combinations are in development, these trials will evaluate the potential of ICS to reduce exacerbations on top of dual bronchodilation.

Although the introduction of these novel combinations is highly welcomed as further improvements in the standard of COPD care are expected, there is also a caveat associated with the advent of multiple-combination inhalers. The availability of different combinations in various inhaler devices containing different drugs with partial or full overlap in pharmacologic mechanism clearly bears a risk of confusion in 
patients and prescribing physicians, potentially leading to misuse of incompatible combinations (e.g., ICS/LABA plus LABA/LAMA) or overdose of single components. Therefore, it will be of outmost importance to inform and educate physicians and patients about specific contents of combination inhalers, their mechanisms, appropriate doses and indications, as well as any incompatibilities with other inhaler products.

\section{ACKNOWLEDGMENTS}

K.M.B. has received compensation for organizing or participating in advisory boards for Almirall Hermal, Cytos, Chiesi, Boehringer Ingelheim, AstraZeneca, Mundipharma, Novartis and Revotar Biopharmaceuticals and participated as a speaker in scientific meetings or courses supported by various pharmaceutical companies (Almirall Hermal, AstraZeneca, Boehringer Ingelheim, Novartis, Pfizer and Takeda) in the past 3 years. K.M.B. has received consulting fees from Ablynx, Apellis Pharmaceuticals, Chiesi and Cytos.

The institution where K.M.B. is employed (insaf Respiratory Research Institute) has received compensations for the design, performance or participation in single or multicentre clinical trials in the past 3 years from several companies including Almirall, Boehringer Ingelheim, Cytos, GSK, Mundipharma, Novartis, Pfizer, Revotar Biopharmaceuticals, Sterna AG, and TEVA.

\section{Conflict of interest. None.}

Open Access. This article is distributed under the terms of the Creative Commons Attribution Noncommercial License which permits any noncommercial use, distribution, and reproduction in any medium, provided the original author(s) and the source are credited.

\section{REFERENCES}

1. Theravance ${ }^{\circledR}$. BREO $^{\circledR}$ ELLIPTA $^{\mathrm{TM}}$ Now available in the US for the treatment of COPD. Available at: http://investor.theravance.com/releasedetail.cfm? ReleaseID $=801611$. Last accessed November 15, 2013.

2. Novartis. Novartis first-in-class once-daily dual bronchodilator Ultibro Breezhaler (QVA149) achieves near simultaneous approval for COPD patients in Europe and Japan. Available at: www. novartis.com/newsroom/media-releases/en/2013/ 1730580.shtml. Last accessed November 15, 2013.

3. Theravance ${ }^{\circledR}$. FDA Advisory Committee Recommends Approval in US of umeclidinium/ vilanterol for the treatment of COPD. Available at http://investor.theravance.com/releasedetail.cfm? ReleaseID $=789930$. Last accessed November 15, 2013.

4. Almirall. Aclidinium and formoterol fixed dose combination for COPD submitted for registration in Europe. Available at http://www.almirall.com/ webcorp2/cda/comunicacion_detalle_noticia.jsp? id=2593. Last accessed November 15, 2013.

5. Vestbo J, Hurd SS, Agusti AG, et al. Global strategy for the diagnosis, management, and prevention of chronic obstructive pulmonary disease. Am J Respir Crit Care Med. 2013;187:347-65.

6. Suissa S, Patenaude V, Lapi F, Ernst P. Inhaled corticosteroids in COPD and the risk of serious pneumonia. Thorax. 2013;68:1029-36.

7. Calverley PMA, Pauwels R, Vestbo J, et al. Combined salmeterol and fluticasone in the treatment of chronic obstructive pulmonary disease: a randomised controlled trial. Lancet. 2003;361:449-56.

8. Dransfield MT, Bourbeau J, Jones PW, et al. Oncedaily inhaled fluticasone furoate and vilanterol versus vilanterol only for prevention of exacerbations of COPD: two replicate doubleblind, parallel-group, randomised controlled trials. Lancet Respir Med. 2013;1:210-23.

9. Martinez FJ, Boscia J, Feldman G, et al. Fluticasone furoate/vilanterol (100/25; 200/25 mcg) improves lung function in COPD: a randomised trial. Respir Med. 2013;107:550-9. 
10. Agusti A, de Teresa L, De Backer W, et al. A comparison of the efficacy and safety of oncedaily fluticasone furoate/vilanterol with twice-daily fluticasone propionate/salmeterol in moderate to very severe COPD. Eur Respir J. 2013. doi:10.1183/ 09031936.00054213.

11. Bateman ED, Ferguson GT, Barnes N, et al. Dual bronchodilation with QVA149 versus single bronchodilator therapy: the SHINE study. Eur Respir J. 2013. doi:10.1183/09031936.00200212.

12. Donohue JF, Maleki-Yazdi MR, Kilbride S, Mehta R, Kalberg C, Church A. Efficacy and safety of oncedaily umeclidinium/vilanterol $62.5 / 25 \mathrm{mcg}$ in COPD. Respir Med. 2013;107:1538-46.

13. Mahler DA, Decramer M, D'Urzo A, et al. Dual bronchodilation with QVA149 reduces patientreported dyspnoea in COPD: BLAZE study. Eur Respir J. 2013. doi: 10.1183/09031936.00124013.

14. Vogelmeier CF, Bateman ED, Pallante J, et al. Efficacy and safety of once-daily QVA149 compared with twice-daily salmeterol/fluticasone in patients with chronic obstructive pulmonary disease (ILLUMINATE): a randomised, doubleblind, parallel group study. Lancet Respir Med. 2013;1:51-60.
15. Wedzicha JA, Decramer M, Ficker JH, et al. Analysis of chronic obstructive pulmonary disease exacerbations with the dual bronchodilator QVA149 compared with glycopyrronium and tiotropium (SPARK): a randomised, double-blind, parallel-group study. Lancet Respir Med. 2013;1:199.

16. Beeh KM, Korn S, Beier J, et al. QVA149 once daily improves exercise tolerance and lung function in patients with moderate to severe COPD: the BRIGHT study. Thorax 2012;67:A147 (Abstract).

17. Maltais F, Singh SJ, Donald A, et al. Effects of a combination of vilanterol and umeclidinium on exercise endurance in subjects with COPD: two randomized clinical trials. Eur Respir J. 2013;P761.

18. Agusti A, Edwards LD, Celli B, et al. Characteristics, stability and outcomes of the 2011 GOLD COPD groups in the ECLIPSE cohort. Eur Respir J. 2013;42:636-46.

19. Vestbo J, Anderson J, Brook RD, et al. The study to understand mortality and morbidity in COPD (SUMMIT) study protocol. Eur Respir J. 2013;41:1017-22. 